\title{
Hypothyroidism during neonatal and perinatal period induced by thyroidectomy of the mother causes depressive-like behavior in prepubertal rats
}

This article was published in the following Dove Press journal:

Neuropsychiatric Disease and Treatment

16 April 2010

Number of times this article has been viewed

\section{Marisol Pineda-Reynoso \\ Edgar Cano-Europa \\ Vanessa Blas-Valdivia \\ Adelaida Hernandez-Garcia \\ Margarita Franco-Colin \\ Rocio Ortiz-Butron}

Departamento de Fisiología 'Mauricio Russek Berman,' Escuela Nacional de Ciencias Biológicas, IPN, Carpio y Plan de Ayala, México
Correspondence: Rocio Ortiz-Butron Escuela Nacional de Ciencias Biológicas, Carpio y Plan de Ayala, México DF, I I 340, México

Tel +52 $57296300 / 62481$

Fax +52 57296206

Email rocipn@yahoo.com.mx

\begin{abstract}
The objective of this study was to see if neonatal and perinatal hypothyroidism caused anxiety and depressive-like behaviors. Twenty female Wistar rats were randomly divided into two groups: 1) thyroidectomy caused hypothyroidism, in which the thyroid gland had been removed and the parathyroid reimplanted; and 2) false thyroidectomy. The thyroidectomy was made on rats anesthetized with ketamine-xylazine. The rats were mated and one day after giving birth, eight pups were assigned to each group randomly and they were distributed into two groups: a hypothyroid group containing male pups of a hypothyroid mother with a hypothyroid wet nurse; and a euthyroid group of male pups of a euthyroid mother with a euthyroid wet nurse. We analyzed the behavioral test at a prepubertal age. The neonatal and perinatal hypothyroidism caused by the mother's thyroidectomy caused a decrease in body weight and length. We found that the neonatal and perinatal hypothyroidism enhanced the total exploratory activity without affecting social contact and the time spent in the open and closed arms in an elevated plus-maze. The hypothyroidism caused immobility without altering the lower climbing duration in the swimming test. This study shows a novel model to cause neonatal and perinatal hypothyroidism without using pharmacological drugs. We demonstrated that hypothyroid animals had a reduction in body weight and length, a retardation of neurodevelopment, and they had depressive-like behavior.
\end{abstract}

Keywords: perinatal hypothyroidism, thyroidectomy, thyroid hormone, behavior, metabolism

\section{Introduction}

The thyroid hormone 3, 5, 3'-triiodothyronine $\left(\mathrm{T}_{3}\right)$ has a fundamental role in the development, differentiation, and physiology of the central nervous system (CNS) in all life stages. ${ }^{1-3}$ It is a regulator of central neurotransmission in both the adult ${ }^{4-6}$ and perinatal ages. ${ }^{7,8}$

Perinatal hypothyroidism is a disorder characterized by a reduction of the thyroid hormone during a critical period of brain development. This state is associated with a profound and often irreversible morphological defect contributing to severe cognitive and neurological impairment related to behavioral changes, such as cognitive dysfunction, attention deficit, and depression. Furthermore, hypothyroid subjects who have psychiatric disorders with hormone replacement therapy reversed the symptoms. ${ }^{9}$ There have been descriptions of hypothyroidism-caused metabolic dysfunction in growth, energetic metabolism, and thyroid hormone secretion by the thyroid gland. ${ }^{10,11}$

However, the majority of studies that related perinatal hypothyroidism to several variables used an antithyroid drug, methimazole, or propylthiouracil to reduce thyroidhormone serum concentration. However, these drugs cause extrathyroid actions ${ }^{12}$ such 
as cellular damage in different organs. ${ }^{13}$ For this reason, it is important to develop models to cause neonatal and perinatal hypothyroidism without modifying other systems, such as using thyroidectomy with a parathyroid reimplant.

The objective of our study was to develop, in rat pups, neonatal and perinatal hypothyroidism caused by thyroidectomy of the mother to prove a behavioral test related to anxiety and depression, and show changes in developmental variables such as body weight and length. It used open-field in an unknown environment, elevated plus-maze, and social interaction to evaluate anxiety-like behaviors. Meanwhile, the forced swimming test was used to evaluate depressivelike behaviors.

\section{Methods}

Twenty female Wistar rats (235-250 g) from our animal care facilities were used. Animals were housed singly (acrylic cages, $20 \times 30 \times 18 \mathrm{~cm}$, with food and water ad libitum). The cages were located together in racks (so that auditory and olfactory contact were maintained) in a light (0800 to 2000 lights on) and temperature $\left(21 \pm 1^{\circ} \mathrm{C}\right)$ controlled room. Food and water were always available. The rats were allowed to acclimatize to the colony-room conditions for at least 1 week before the start of the experiments.

All animal procedures were done in accordance with the guidelines of the Laws and Codes of Mexico in The Seventh Title of the Regulations of the General Law of Health Regarding Health Research.

\section{Experimental design}

The rats were randomly divided into two groups: 1) thyroidectomy-caused hypothyroidism, in which rats had their thyroid gland removed and the parathyroid reimplanted $(n=10)$; and 2 ) false thyroidectomy $(n=10)$. Thyroidectomy was done on rats anesthetized with ketamine (10 mg/kg, im)-xylazine ( $5 \mathrm{mg} / \mathrm{kg}$, im). We used the method previously described. ${ }^{13}$ Briefly, by using a stereomicroscope (Zeiss, Germany) for better observation, the stenothyroid muscle was cut and the trachea was exposed. The parathyroid gland was located, dissected from the thyroid gland, and reimplanted into the surrounding neck muscle. The thyroid gland was carefully dissected out to avoid injury to the laryngeal nerve and was completely excised. After surgery ketorolac $(50 \mathrm{mg} / \mathrm{kg}, \mathrm{im})$ and gentamicin $(10 \mathrm{mg} / \mathrm{kg}, \mathrm{im})$ were administered over 5 days to alleviate pain and prevent infection.

After recovering from the surgery, three females were put with one male in a plastic cage for mating and only the thyroidectomized rats received a dose of $\mathrm{T}_{4}(20 \mu \mathrm{g} / \mathrm{kg} /$ week sc during three gestation weeks). One day after birth, pups were assigned randomly to each group and they were distributed into two groups as: hypothyroid group; male pups of hypothyroid mother with a hypothyroid wet nurse $(n=24$, eight pups per nurse) or euthyroid group; male pups of euthyroid mother with an euthyroid wet nurse $(n=24$, eight pups per nurse).

At birth we quantified the number of pups. The neurodevelopment of pups was evaluated indirectly by the day on which the pups opened their eyes. The serum thyroid hormone concentration was evaluated in pumps at birth and one day after the behavioral procedure. At birth we used eight male pups of each group, meanwhile at prepuberal age we used sixteen male rats per group. The serum was separated and stored at $-70^{\circ} \mathrm{C}$ until assayed. The $\mathrm{T}_{3}$ and $\mathrm{T}_{4}$ concentrations were later determined by an enzyme immunoassay (ICN Pharmaceuticals, USA).

Pups were weaned at 21 posnatal, and during all treatment (P38), we measured the body weight and length three times a week. At weaning eight rats of same group were allocated in acrylic cages, $20 \times 30 \times 18 \mathrm{~cm}$, with food and water ad libitum.

\section{Behavioral procedure}

All behavioral testing was done between 0900 and 1300 and was recorded on videotape using a VHS video camera (NV-N3000PN, Panasonic). We analyzed the behavioral test at prepubertal age (P33-P37). The test time of day was balanced across experimental groups. We used open-field test in an unknown environment, social contact to prove anxietylike behavior. Meanwhile, swimming forced test was used to evaluate depressive-like behavior.

\section{Open-field test in an unknown environment}

The open-field test in an unknown environment was made on P33. ${ }^{14}$ In this test, the automatic activity counter consists of an acrylic cage measuring $51.1 \times 9.5 \times 69.2 \mathrm{~cm}$ with two arrays of 15 infrared beams, with the arrays placed perpendicular to one other. The beams are spaced $2.5 \mathrm{~cm}$ apart. The interruption of each beam generates an electric impulse, which is processed and presented as a count (Opto-Varimex; Columbus Instruments, Ohio, USA). The total activity over a 5-min session was recorded. After each trial, the rats were returned to the colony room and the area was cleaned with ethanol and a neutral detergent. The test time was balanced across experimental groups. 
A

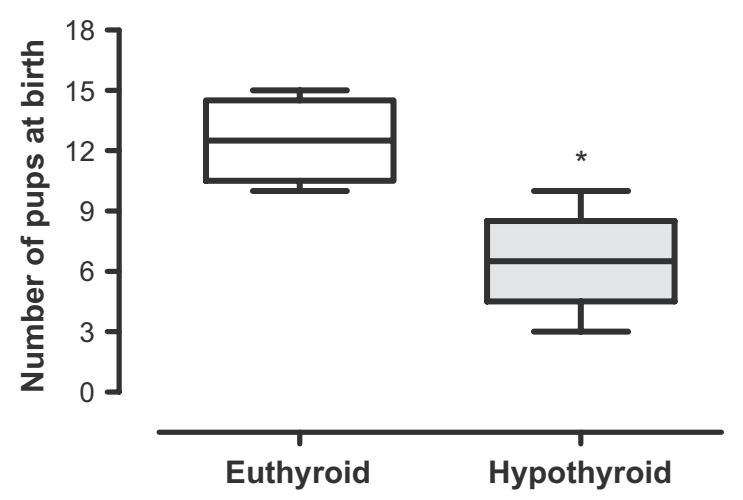

B

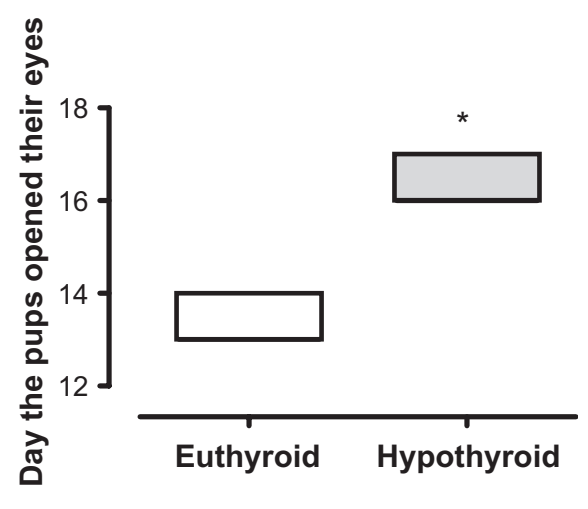

Figure I Indirect evaluation of mother's thyroid state (number of pups at birth, panel $(\mathbf{A})$ and the indirect evaluation of the neurodevelopment of pups (day the pups opened their eyes, panel (B). $* P<0.05$ vs euthyroid group. U-Mann-Whitney test $(n=16)$.

\section{Social contact test}

We evaluated social contact as previously described. ${ }^{15}$ Twenty-four hours before the test on P33, animals were singly housed in a metallic cage $(20 \times 30 \times 18 \mathrm{~cm})$ with food and water ad libitum. The cages were located together in racks for maintaining auditory and olfactory contact. The test was made in an open arena $(60 \times 60 \times 30 \mathrm{~cm})$. The floor was made of smooth black wood. The light conditions were comparable to the light intensity in the housing room; two 39-W overhead fluorescent bulbs were suspended $180 \mathrm{~cm}$ above the center of the field and provided $210 \mathrm{Lx}$ at the floor. The next day (P34) the rats were brought in an individual plastic cage to the testing area, which was in the same building and floor as the colony room. Two animals from the same experimental group were placed on the testing area and 10 min of their social interaction was videotaped and automatically analyzed by the Videomex V apparatus (Columbus Instruments,
Columbus, OH, USA). After each trial, the rats were returned to the colony room and the area was cleaned with a detergent. The social contact program provides a simple method for recording the interaction between two animals. It gives the total number of contacts during the experiment and the total amount of time the animals have been in contact.

\section{Elevated plus-maze test}

The plus-maze has two open and two enclosed arms $(50 \times$ $10 \times 40 \mathrm{~cm}$ ) mounted $50 \mathrm{~cm}$ above the floor. ${ }^{16}$ The floor of the arms was smooth. White fluorescent tubes $(39 \mathrm{~W})$ were mounted above the maze so that all arms were equally illuminated with $210 \mathrm{Lx}$. For this experiment, separate groups of animals (singly housed) were used. On P35, the rat was placed in the central platform of the apparatus facing an enclosed arm. A camera on the ceiling of the test room was used to record the experiment for $3 \mathrm{~min}$. A person blind to
A

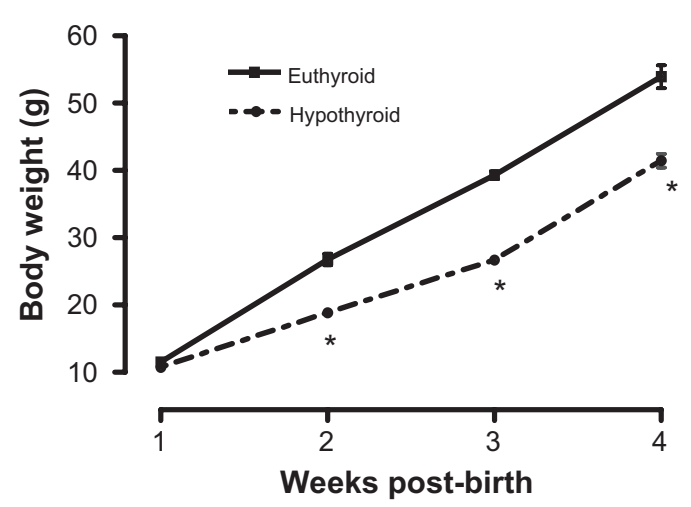

B

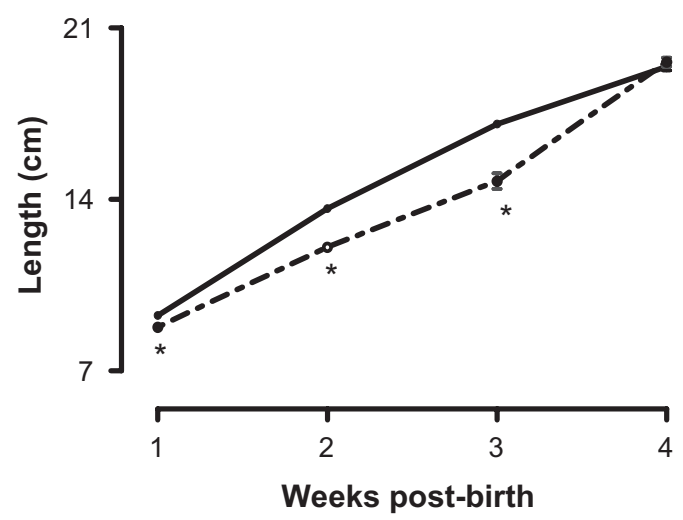

Figure 2 Effect of perinatal hypothyroid on body weight $(\mathbf{A})$ and length $(\mathbf{B}) 4$ weeks post birth $(n=16)$. $* P<0.05$ vs euthyroid group at same week. R-M two-way ANOVA and Student-Newmann-Keuls post hoc. 
the animal's treatment evaluated the time spent in the open and closed arm. Arm entry was defined as all four feet on the arm. The maze was cleaned following each trial.

\section{Forced swimming test}

The test was made using the method described. ${ }^{17}$ Briefly, prepubertal rats were individually forced to swim in open cylinders $(25 \mathrm{~cm}$ height $\times 10 \mathrm{~cm}$ diameter $)$ containing $19 \mathrm{~cm}$ of water at $25 \pm 1{ }^{\circ} \mathrm{C}$. This procedure was done in two days. The first day is for the pretest and the second day the test was evaluated. On P36 (pretest) the animals were put in the cylinder for 15 minutes. On the test day (P37) the animals were put in the cylinder for only 5 minutes. We analyzed the swimming, climbing, and immobility durations. After each test, the animals were dried with a towel and they were put into a plastic cage in the colony room.

\section{Statistical analysis}

The number of pups at birth and the day the pups opened their eyes were given as the median (percentile intervals). All the other variables evaluated were given as the mean (SE). The statistical analysis for nonparametric variables was evaluated by the U-Mann-Whitney test. The body weight and length were evaluated by a repeated measures two-way ANOVA and a post hoc Newman-Student-Keuls test. The behavioral test were analyzed by a Student's $t$-test. $P$ less than 0.05 was considered statistically significant.

\section{Results}

Panel A of Figure 1 shows that a hypothyroid mother caused by thyroidectomy with a parathayroid reimplant (Tx) has fewer pups than those with a false thyroidectomy that are euthyroid $(=10.5, P<0.01)$. Panel B of Figure 1 shows that the hypothyroid pups open their eyes later than the euthyroid pups $(U=360, P<0.001)$.
Table I Quantification of serum thyroid hormone in euthyroid and hypothyroid rats

\begin{tabular}{lll}
\hline Serum concentration $(\mathrm{nmoles} / \mathrm{L})$ & Groups \\
\cline { 2 - 3 } & Euthyroid & Hypothyroid \\
\hline $\mathrm{T}_{3}$ at birth $(n=8)$ & $0.76 \pm 0.14$ & $0.30 \pm 0.02 *$ \\
$\mathrm{~T}_{3}$ at prepubertal age P38 $(n=16)$ & $1.01 \pm 0.07$ & $0.69 \pm 0.09 *$ \\
$\mathrm{~T}_{4}$ at birth $(n=8)$ & $20.55 \pm 5.03$ & $15.08 \pm 7.20$ \\
$\mathrm{~T}_{4}$ at prepubertal age P38 $(n=16)$ & $32.48 \pm 4.70$ & $45.80 \pm 9.59$ \\
\hline
\end{tabular}

$* P<0.05$ vs euthyroid group. Student's $t$-test.

Figure 2 shows the effect of perinatal hypothyroidism on body weight (panel A) and length (panel B). Perinatal hypothyroidism caused by the Tx mother caused a decrease in body weight and length (for body weight week: $F=534.9$, $P<0.001$; thyroid state: $F=3301.6, P<0.001$; interaction week $\times$ thyroid state: $F=3301.6, P<0.001$; for length week: $F=2334, P<0.001$; thyroid state: $F=48.7, P<0.001$; interaction week $\times$ thyroid state: $F=31.9, P<0.001$ ).

The thyroid state of animals was corroborated by serum determination. In Table 1 , it is shown that $\mathrm{T}_{3}$ is lower in perinatal hypothyroid rats at birth and on $\mathrm{P} 36$ than euthyroid rats (at birth: $t=3.25, P<0.005$; at P36: $t=2.81, P<0.01$ ). The $\mathrm{T}_{4}$ concentration did not change (at birth: $t=0.62, P=0.54$; at P36: $t=1.24, P=0.22$ ).

The effect of perinatal hypothyroidism in the open-field test is shown in Figure 3. The neonatal and perinatal hypothyroid rats had an enhanced total exploratory activity (panel A, $t=2.46, P<0.05$ ) because of increased ambulatory activity or horizontal activity (panel $\mathrm{B}, t=2.21, P<0.05$ ). In this test, the vertical activity was not modified (panel C, $t=0.34$, $P=0.75)$.

The neonatal and perinatal hypothyroidism did not affect the time spent on the open (panel A Figure 4; $t=1.09$, $P=0.29$ ) and enclosed arms (panel B Figure $4 ; t=0.29$, $P=0.77)$ in the elevated plus-maze. The number of social
A

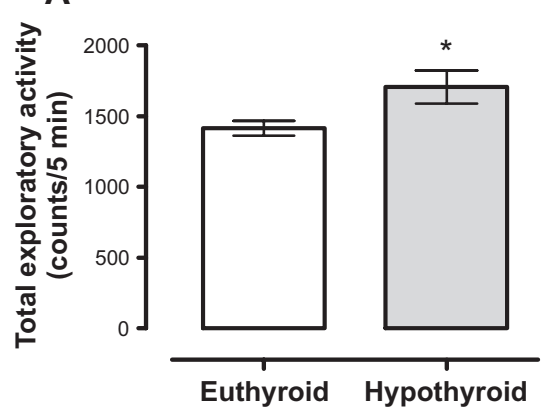

B

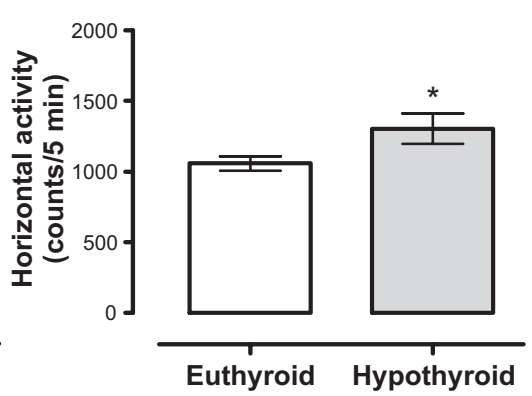

C

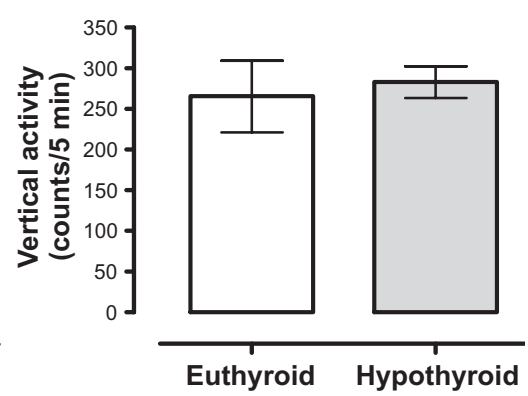

Figure 3 Effect of perinatal hypothyroid on the open field test at prepubertal age. We evaluated total exploratory activity (A), horizontal activity (B), and vertical activity (C) $(n=16) . * P<0.05$ vs euthyroid group. Student's $t$-test. 

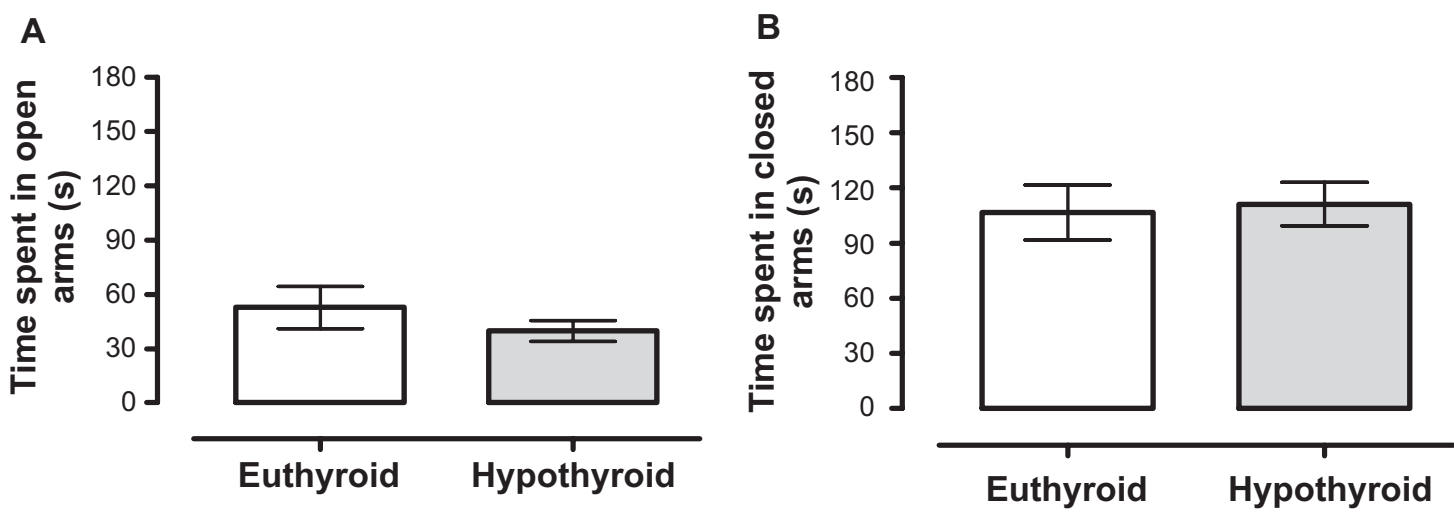

Figure 4 Effect of perinatal hypothyroid on elevated plus-maze test at prepubertal age. We evaluated time spent in open $(\mathbf{A})$ or enclosed $(\mathbf{B})$ arms $(n=16)$.

contacts (panel A Figure $5 ; t=1.62, P=0.14$ ) and time spent in social contact (panel B Figure $5 ; t=0.27, P=0.78$ ) were not modified by neonatal and perinatal hypothyrodism.

In Figure 6 we present the effect of perinatal hypothyroidism on the forced swimming test. We observed that immobility in hypothyroid rats is enhanced compared with euthyroid animals (panel A, $t=2.21, P<0.05$ ). Hypothyroid rats have a lower climbing duration than euthyroid rats (panel $\mathrm{B}, t=3.15$, $P<0.005)$. Swimming in this test did not change because of the treatments (panel $\mathrm{C}, t=0.56, P<0.58$ ).

\section{Discussion}

Thyroid hormones play an important role during fetal development and they are essential for the proper development of the central nervous system. Thus, perinatal hypothyroidism causes abnormal neurodevelopment and behavioral alteration in the pups. ${ }^{18}$ This condition is caused by the antithyroid drug administration at different times during the embryonic development. However, controversial findings have been observed in the behavioral test because this method uses different antithyroid drugs, methimazole, or propylthiouracil. There are other variables influencing the experiment such as the time of antithyroid drug treatment and dose. It has been demonstrated that antithyroid drugs cause extra-thyroid effects such as cellular damage. ${ }^{13}$ All of these factors make it difficult to study the effects of neonatal and perinatal hypothyroidism per se. The aim of our work was to evaluate a behavioral test related to anxiety and depression in the pups of a mother thyroidectomized with a parathyroid gland reimplant. We thus eliminate the effect of the drugs on neonatal and perinatal hypothyroidism.

For developmental parameter, we found that hypothyroid mother has a fewer number of pups. The hypothyroid pups have opened their eyes later than the euthyroid pups. The hypothyroid pups had decreased body weight and length during the first four weeks of life, and have a decreased $\mathrm{T}_{3}$ at birth and on P38.

The litter size of hypothyroid rats was lower than that of the euthyroid rats, as well as that described for partially thyroidectomized rats. ${ }^{10}$ At birth the hypothyroid pups are
A

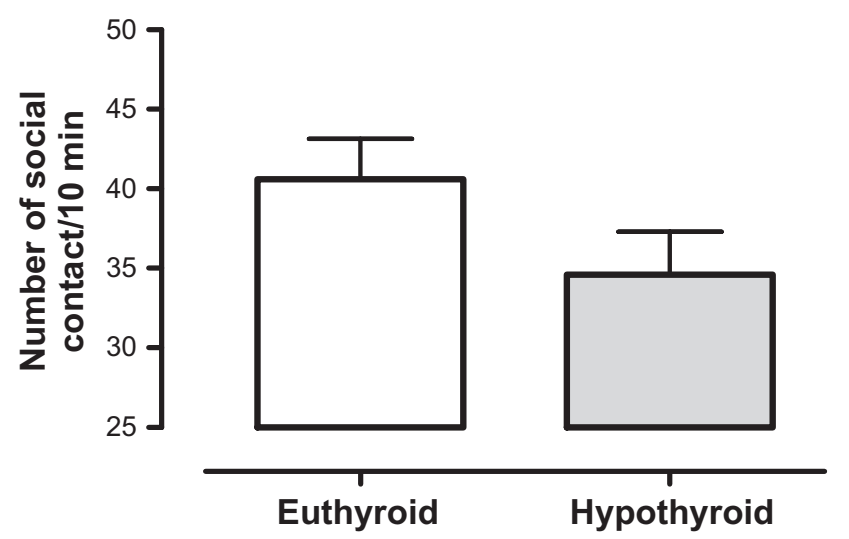

B

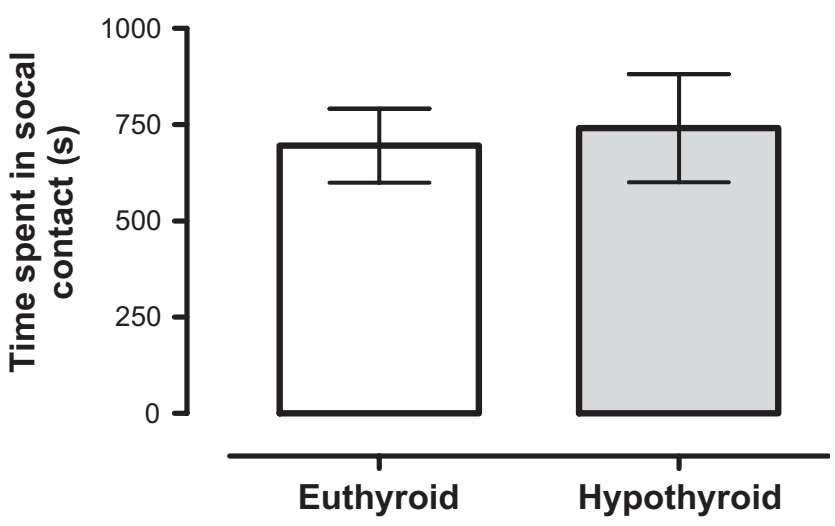

Figure 5 Effect of perinatal hypothyroid on number of social contacts $(\mathbf{A})$ and on time spent in social contact $(\mathbf{B})$ at prepubertal age $(n=16)$. 
A

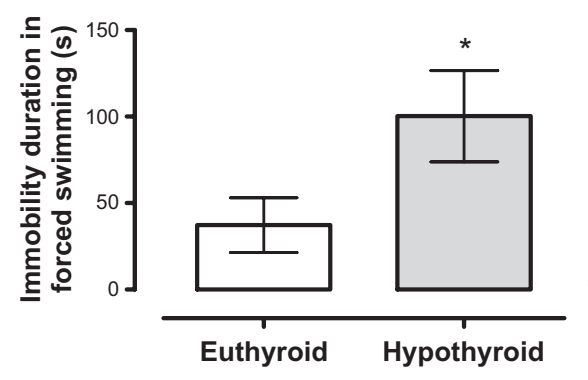

$B$

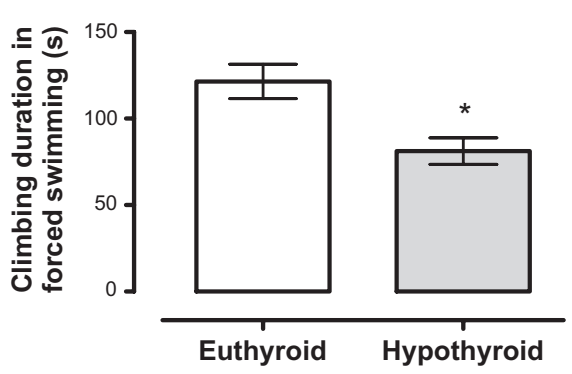

C

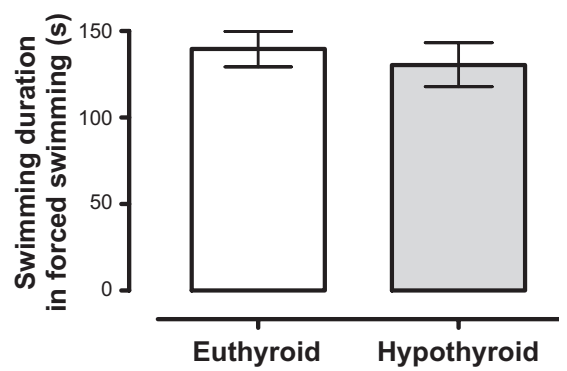

Figure 6 Effect of perinatal hypothyroid on the forced swimming test at prepubertal age. We evaluated immobility $(\mathbf{A})$ climbing $(\mathbf{B})$ and swimming $(\mathbf{C})$ duration $(\mathrm{n}=16)$, $* P<0.05$ vs. euthyroid group. Student's $t$-test.

smaller than euthyroid pups and they appear to be developmentally immature, as others have demonstrated. ${ }^{19,20}$

Hypothryoid pups had a lower body weight than euthyroid pups from birth to prepubertal age. This can be explained because hypothyroid rats had an enhanced transcription of mRNA for leptin ${ }^{21}$ and its concentration in serum..$^{22}$ Leptin acts on the hypothalamus producing an anorexigenic effect so that hypothyroid pups have a lower appetite than euthyroid animals. The milk quality of hypothyroid dams is poor because it has less nutrients such as triglycerides and proteins because of reduced lipogenic enzymes and protein synthesis. ${ }^{23}$

For the pups' length, the hypothyroids were smaller than euthyroids during the prepubertal age. Some studies had proposed that hypothyroidism reduced body growth in the prepubertal age because of a thyroid-hormone reduced basal metabolic rate ${ }^{11}$ and stated that this affects metabolic programming. ${ }^{10}$

The perinatal hypothyroid state was corroborated by thyroid hormone determination. We found that hypothyroid animals had lower levels of $\mathrm{T}_{3}$ than the euthyroid animals. We found that hypothyroid pups open their eyes later than euthyroid pups. This implied an alteration in neurodevelopment because a deficiency of thyroid hormone causes a retardation of the development of the CNS..$^{18}$ Other tests that reveal alteration in the CNS are the behavioral tests. The deficiency of the thyroid hormone in the early stages of development could lead to structural changes at different brain levels, which modify long-term behavioral responses because the thyroid hormones are important to maintain the metabolic functioning of neurons during the life cycle of the rat. ${ }^{18,24}$ We found that hypothyroid pups have an enhanced exploratory activity in a novel environment without affecting anxiety-related behavior evaluated in the elevated plus-maze and social interaction tests at a prepubertal age. These animals have an increased immobility duration with a decrease in scaling time in the forced swimming test.
The results of the open-field test were similar to the data found by other investigators. ${ }^{25,26} \mathrm{We}$ found an increase of total activity. This test is traditionally considered to be indicative of hyperreactivity and an anxiety behavior of rats. However, more sensitive tests to evaluate anxiety, the elevated plusmaze and social interaction, did not reveal anxiety-related behavior. The increased exploratory activity during the prepubertal age could be related to abnormal ontogenetics of the test. It is well established that the development of exploratory activity has a U-shaped curve as a function of age. ${ }^{27}$ Thus, neonatal and perinatal hypothyroidism did not cause anxiety-like behavior.

However, the most relevant finding of our study was the depressed behavior observed in hypothyroid prepubertal rats. We saw a reduction of climbing and an enhanced immobility in the forced swimming test. It has been demonstrated that catecholamines, serotonin, and noradrenaline modulate climbing and immobility responses in the forced swimming test. ${ }^{28}$ Therefore this result supports the idea that hypothyroidism changes the central neurotransmission. ${ }^{5}$ It is possible that the neonatal and perinatal hypothyroidism decreased the response of the serotonergic and noradrenergic systems because it affects the intracellular signaling transduction. ${ }^{29}$ Furthermore, hypothyroidism may alter the serotonergic and noradrenergic systems in the same way, both in the neonatal and perinatal period and in adults. ${ }^{30}$

This study presents a novel model to cause neonatal and perinatal hypothyroidism without pharmacological drug use. We demonstrated that hypothyroid animals had a reduction in body weight and lenth, a retardation of their neurodevelopment, and depressive behavior.

\section{Acknowledgments}

Thanks to Dr Ellis Glazier for editing this English-language text. 


\section{Disclosures}

The authors report no conflicts of interest in this work.

\section{References}

1. Oppenheimer JH, Schwartz HL, Strait KA. Thyroid hormone action 1994: the plot thickens. Eur J Endocrinol. 1994;130:15-24.

2. Loosen PT. Effects of thyroid hormones on central nervous system in aging. Psychoneuroendocrinology. 1992;17:355-374.

3. Desouza LA, Ladiwala U, Daniel SM, Agashe S, Vaidya RA, Vaidya VA. Thyroid hormone regulates hippocampal neurogenesis in the adult rat brain. Mol Cell Neurosci. 2005;29:414-426.

4. Vaccari A. Decreased central serotonin function in hypothyroidism. Eur J Pharmacol. 1982;82:93-95.

5. Ortiz-Butron R, Pacheco-Rosado J, Hernandez-Garcia A, Briones-Velasco M, Rocha L. Mild thyroid hormones deficiency modifies benzodiazepine and mu-opioid receptor binding in rats. Neuropharmacology. 2003;44:111-116.

6. Hemmings SJ, Shuaib A. Hypothyroidism-evoked shifts in hippocampal adrenergic receptors: implications to ischemia-induced hippocampal damage. Mol Cell Biochem. 1998;185:161-169.

7. Cai D, Su Q, Chen Y, Luo M. Effect of thyroid hormone deficiency on developmental expression of goalpha gene in the brain of neonatal rats by competitive RT-PCR and in situ hybridization histochemistry. Brain Res. 2000;864:195-204.

8. Savard P, Merand Y, Di Paolo T, Dupont A. Effect of neonatal hypothyroidism on the serotonin system of the rat brain. Brain Res. 1984;292:99-108.

9. Porterfield SP, Hendrich CE. The role of thyroid hormones in prenatal and neonatal neurological development-current perspectives. Endocrinol Rev. 1993;14:94-106.

10. Pickard MR, Leonard AJ, Ogilvie LM, et al. Maternal hypothyroidism in the rat influences placental and liver glycogen stores: fetal growth retardation near term is unrelated to maternal and placental glucose metabolic compromise. J Endocrinol. 2003;176:247-255.

11. Hulbert AJ. Thyroid hormones and their effects: a new perspective. Biol Rev Camb Philos Soc. 2000;75:519-621.

12. Bandyopadhyay U, Biswas K, Banerjee RK. Extrathyroidal actions of antithyroid thionamides. Toxicol Lett. 2002;128:117-127.

13. Cano-Europa E, Blas-Valdivia V, Franco-Colín M, GallardoCasas CA, Ortiz-Butron R. Methimazole-induced hypothyroidism caused cellular damage in spleen, heart, liver, lung and kidney. Acta histochemica. In press.

14. Briones-Aranda A, Castillo-Salazar M, Picazo O. Adrenalectomy modifies the hippocampal 5-HT(1A) receptors and the anxiolyticlike effect of 8-OH-DPAT in rats. Pharmacol Biochem Behav. 2009;92:182-189.

15. Blas-Valdivia V, Cano-Europa E, Hernandez-Garcia A, OrtizButron R. Neonatal bilateral lidocaine administration into the ventral hippocampus caused postpubertal behavioral changes: an animal model of neurodevelopmental psychopathological disorders. Neuropsychiatr Dis Treat. 2009;5:15-22.
16. Becker A, Grecksch G, Bernstein HG, Hollt V, Bogerts B. Social behaviour in rats lesioned with ibotenic acid in the hippocampus: quantitative and qualitative analysis. Psychopharmacology (Berl). 1999; 144:333-338.

17. Porsolt RD, Brossard G, Hautbois C, Roux S. Rodent models of depression: forced swimming and tail suspension behavioral despair tests in rats and mice. Curr Protoc Neurosci. 2001 May; Chapter 8: Unit 8. 10A.

18. Bernal J. Thyroid hormone receptors in brain development and function. Nat Clin Pract Endocrinol Metab. 2007;3:249-259.

19. Bakke JL, Lawrence NL, Robinson S, Bennett J. Endocrine studies of the untreated progeny of thyroidectomized rats. Pediatr Res. 1975;9:742-748

20. Hendrich CE, Jackson WJ, Porterfield SP. Behavioral testing of progenies of Tx (hypothyroid) and growth hormone-treated Tx rats: an animal model for mental retardation. Neuroendocrinology. 1984;38: 429-437.

21. Karakoc A, Ayvaz G, Taneri F, et al. The effects of hypothyroidism in rats on serum leptin concentrations and leptin mRNA levels in adipose tissue and relationship with body fat composition. Endocr Res. 2004;30:247-255.

22. Escobar-Morreale HF, Escobar del Rey F, Morreale de Escobar G. Thyroid hormones influence serum leptin concentrations in the rat. Endocrinology. 1997;138:4485-4488.

23. Hapon MB, Varas SM, Jahn GA, Gimenez MS. Effects of hypothyroidism on mammary and liver lipid metabolism in virgin and late-pregnant rats. J Lipid Res. 2005;46:1320-1330.

24. Montero P, Venero C, Lavado-Autric R, et al. Modulation of adult hippocampal neurogenesis by thyroid hormones: implications in depressive-like behavior. Mol Psychiatry. 2006;11:361-371.

25. Darbra S, Garau A, Balada F, Sala J, Marti-Carbonell MA. Perinatal hypothyroidism effects on neuromotor competence, novelty-directed exploratory and anxiety-related behaviour and learning in rats. Behav Brain Res. 2003;143:209-215.

26. Negishi T, Kawasaki K, Sekiguchi S, et al. Attention-deficit and hyperactive neurobehavioural characteristics induced by perinatal hypothyroidism in rats. Behav Brain Res. 2005;159:323-331.

27. Ba A, Seri BV. Psychomotor functions in developing rats: ontogenetic approach to structure-function relationships. Neurosci Biobehav Rev. 1995; 19:413-425.

28. Borsini F. Role of the serotonergic system in the forced swimming test. Neurosci Biobehav Rev. 1995;19:377-395.

29. Penela P, varez-Dolado M, Munoz A, Mayor F. Expression patterns of the regulatory proteins $\mathrm{G}$ protein-coupled receptor kinase 2 and betaarrestin 1 during rat postnatal brain development: effect of hypothyroidism. Eur J Biochem. 2000;267:4390-4396.

30. Kulikov A, Torresani J, Jeanningros R. Experimental hypothyroidism increases immobility in rats in the forced swim paradigm. Neurosci Lett. 1997;234:111-114.
Neuropsychiatric Disease and Treatment

\section{Publish your work in this journal}

Neuropsychiatric Disease and Treatment is an international, peerreviewed journal of clinical therapeutics and pharmacology focusing on concise rapid reporting of clinical or pre-clinical studies on a range of neuropsychiatric and neurological disorders. This journal is indexed on PubMed Central, the 'PsycINFO' database and CAS, and is the official

\section{Dovepress}

journal of The International Neuropsychiatric Association (INA). The manuscript management system is completely online and includes a very quick and fair peer-review system, which is all easy to use. Visit http://www.dovepress.com/testimonials.php to read real quotes from published authors. 